\title{
Studying the central control of food intake and obesity in rats
}

\author{
Estudando em ratos o controle central da \\ ingestão alimentar e a obesidade
}

Eliane Beraldi RIBEIRO'

The central nervous system regulates energy intake and expenditure through a complex network of neurotransmitters and neuromodulators. It is of great interest to understand the relevance of these systems to the physiological control of energy balance and to the disturbances of obesity. The present paper discusses some of the methods to address this field used at the laboratory of Endocrine Physiology of Universidade Federal de São Paulo. Initially, different experimental models of rat obesity are presented, namely the hypothalamic induced monosodium glutamate model, the Zucker genetic model, and the dietary model. The principles of brain microdialysis are also presented, the technique applied to obtain representative samples of the extracellular fluid of brain sites involved in feeding control. The microdialysate levels of serotonin, an important anorexigenic neurotransmitter, are determined by HPLC with electrochemical detection. The immunoblot technique (Western blot) is used to determine hypothalamic levels of proteins relevant to the anorexigenic effect of serotonin and to analyze the acute activation of the insulin signaling cascade in the hypothalamus. The final section addresses the potential applications of proteomics in the study of the central control of feeding.

Indexing terms: Brain microdialysis. Experimental Studies. Food intake. Hypothalamus. Obesity. Rats.

\section{RE S U M O}

O sistema nervoso central controla a ingestão e o gasto de energia por meio de um complexo circuito de neurotransmissores e neuromoduladores. É de grande interesse entender a relevância fisiológica destes sistemas e o papel que desempenham nos distúrbios da obesidade. No presente artigo, discutem-se alguns dos métodos que têm sido utilizados no laboratório de Fisiologia Endócrina da Universidade Federal de São Paulo, em estudos neste campo. Inicialmente, são apresentados alguns modelos de obesidade experimental em ratos, como a obesidade hipotalâmica induzida por glutamato monossódico, o modelo genético Zucker e também obesidades induzidas por dieta. Comenta-se, em seguida, sobre os princípios da microdiálise cerebral. Esta técnica é utilizada para obter amostras representativas do líquido extracelular de regiões cerebrais

\footnotetext{
${ }^{1}$ Universidade Federal de São Paulo, Departamento de Fisiologia, Disciplina de Fisiologia da Nutrição. R. Botucatu, 862, $2^{\circ}$ andar, Vila Clementino, 04023-062, São Paulo, SP, Brasil. E-mail: <eliane.beraldi@unifesp.br>.
} 
envolvidas no controle da ingestão alimentar. Os níveis de serotonina, um importante neurotransmissor anorexígeno, são medidos no dialisato por cromatografia líquida de alta pressão com detecção eletroquímica. Utiliza-se a técnica de immunoblot (Western blot) para determinar os níveis hipotalâmicos de proteínas importantes na ação anorexigênica da serotonina e também para analisar a ativação aguda da cascata de sinalização da insulina no hipotálamo. A seção final aborda o grande potencial da análise proteômica no estudo do controle central da ingestão.

Termos de indexação: Microdiálise cerebral. Estudos experimentais. Ingestão de alimentos. Hipotálamo. Obesidade. Ratos.

\section{NTRODUCTION}

Body energy homeostasis depends on the equilibrium of food intake and energy expenditure and is influenced by multiple factors, of genetic, metabolic, endocrine, neural, behavioral, and environmental nature. All these factors may be potentially involved in the pathogenesis of obesity, although their relative participation may differ among the different obesity syndromes.

A complex central nervous system (CNS) circuit regulates food intake and energy expenditure. Pivotal to this control are the peripheral hormones, leptin, insulin and ghrelin, which act as adiposity and satiety signals, respectively, to the CNS. The neurons of the arcuate nucleus (ARC) of the hypothalamus are the main target of these circulating signals. The ARC neurons express anabolic (orexigenic) and catabolic (anorexigenic) neurotransmitters and they innervate the medial nuclei (ventromedial $\mathrm{VMH}$ - and paraventricular - PVN) and the lateral hypothalamus (LH). Additionally, food intake is modulated by cortico-limbic brain structures, such as the amygdala, prefrontal cortex, and nucleus accumbens shell, which relay to the $\mathrm{LH}$ information concerning the hedonic aspects of food. Through these interactions, sensorial (taste, appearance, smell, texture, etc.) and reward aspects exert a powerful influence upon the homeostatic metabolic control. Disruption of these complex physiological interactions may lead to hyperphagia and/or hypometabolism, the ultimate disturbances of obesity $^{1,2}$

Rodents represent a very useful tool to approach this field. The present paper discusses some of the techniques that have been applied, at the laboratory of Endocrine Physiology of Universidade Federal de São Paulo (Unifesp), to address the physiological and pathophysiological relevance of hypothalamic mediators to feeding homeostasis and obesity. Serotonin and insulin, among others, and, more recently, glucose and nitric oxide, are the mediators that have been focused.

Serotonin is produced in the raphe nuclei and released throughout the brain. Serotonergic innervation of the hypothalamus exerts an important anorexigenic action. Brain microdialysis is performed to estimate how hypothalamic serotonergic activity responds to different experimental manipulations, in both normal and obese rats. The microdialysate levels of serotonin (5-HT) and of its main metabolite, 5-hydroxiindolacetic acid (5-HIAA), are determined by high pressure liquid chromatography (HPLC) coupled with electrochemical detection. Additionally, the immunoblot (Western blot) technique is used to determine hypothalamic tissue levels of proteins important to serotonin anorexigenic action, such as the receptor subtypes 5-HT1B and 5-HT2C and the serotonin transporter protein. Immunoblot has also been used to analyze the acute activation of the insulin signaling cascade in the hypothalamus. The potential of proteomics in the study of the central control of feeding is briefly commented in the final section.

\section{Producing the experimental "subjects": rodent obesity models}

Modeling human obesity in rats and mice offers a rich tool to explore the multifactorial nature 
of the disease. The various models reproduce differently the diversity of obesity syndromes.

\section{Hypothalamic obesity induced by Monosodium Glutamate (MSG): a non-hyperphagic model}

MSG is a potent neuroexcitatory aminoacid. When administered to a newborn animal, it penetrates the SNC through the circunventricular structures, due to their lack of a fully developed blood brain barrier. Accumulating specially in the ARC, MSG causes an excess of neuronal stimulation and destroys $80-90 \%$ of the ARC neurons. The treatment protocol involves the subcutaneous injection of MSG in the dose of $4.0 \mathrm{mg} / \mathrm{g}$ b.w., every second day, during the first 10 days of life. After weaning, the animals are fed a balanced diet until adulthood ${ }^{3-7}$.

The ARC is an important hypothalamic site for energy homeostasis, with a high density of leptin and insulin receptors being expressed in the anorexigenic proopiomelanocortin (POMC) and cocaine-and amphetamine-regulated transcript (CART) neurons as well as in the orexigenic neuropeptide Y (NPY) and agouti-related protein (AgRP) neurons ${ }^{1,2}$. The destruction of these neurons very early in life leads to multiple disturbances. Rats treated neonatally with MSG develop into obese and stunted adults, whose body weight is not elevated but whose body composition is abnormal, with increased fat and decreased lean body mass. Importantly, the MSG-obese rats are not hyperphagic and their excess body fat is caused mainly by a low metabolism and depressed thermogenesis rate ${ }^{3-7}$.

\section{The Zucker genetic obesity}

Although monogenic forms of obesity are rare in humans, the study of single-gene mutated animal models, such as the ob/ob, $d b / d b$, and agouti mice, and the fa/fa rats represents a good material to understand the syndrome.
The obesity of the Zucker rat strain is caused by a spontaneous recessive mutation at the $f a$ locus (also called $d b$ locus), that is responsible for the synthesis of the leptin receptor (LR) protein. The mutation, a single $A$ to $C$ change in codon 880 , leads to a glutamine to proline substitution in residue 269 , in the extracellular domain of the LR protein. The fa/fa rats produce a truncated and inactive $L R$ and are thus resistant to the hypothalamic anorexigenic action of leptin, becoming hyperphagic and morbidly obese, despite their hyperleptinemia. Obese fa/fa rats also present hyperinsulinemia, insulin resistance, glucose intolerance, and hyperlipidemia. The heterozygotes for the mutation $(\mathrm{Fa} / \mathrm{fa})$ and the dominant homozygotes $(\mathrm{Fa} / \mathrm{Fa}$ ) are lean 5,8-10.

Obese Zucker rats are either sterile or unable to mate and the maintenance of a Zucker colony relies almost exclusively on the breeding of lean heterozygotes, that are phenotypically identical to the lean homozygotes. At Universidade Federal de São Paulo (Unifesp), the heterozygotes for breeding are currently being identified at the main animal facility by a PCR assay ${ }^{8}$. Briefly, when the animals are 1-mo-old, their genomic DNA is purified from a tail fragment, amplified, and the product $(1.8 \mathrm{~kb})$ digested with the enzyme Msp1. The product of the wild type gene has a single restriction site for the enzyme, yielding 2 bands in the agarose gel, of $1000 \mathrm{bp}$ and $700 \mathrm{bp}$. In the product generated from the mutated gene, there are two restriction sites and the 1100 bp fragment is further cleaved, to yield $950 \mathrm{bp}$ and $150 \mathrm{bp}$ fragments ${ }^{8-10}$.

\section{Dietary obesity}

The easy access to hypercaloric and palatable foods, rich in fats and/or carbohydrates, is recognized as a major causal factor in the recent obesity epidemic. Diet-induced obesity (DIO) in rodents is considered to more closely reproduce the "common" type of the human disease. Fat and carbohydrates are palatable to the rat and the exposure to these diets is able to affect the 
hedonic component of feeding and induce overeating. However, similarly to what is seen in humans, the susceptibility to DIO in rats is variable and not all exposed individuals will become obese. This is likely due to the interactions of the diets with the genetic, metabolic, endocrine, neural, and behavioral factors which determine predisposition to obesity ${ }^{11,12}$. Understanding how these diets interfere with the physiological systems that control energy homeostasis has been the aim of many studies and different types of high-fat diets have been used. When selecting a diet composition, it is important to consider that not only the caloric density, but also the fatty acid profile, is relevant to the determination of the "obesogenic" capacity of dietary fat. Studies in rodents indicate that mainly the saturated fatty acids, but also the polyunsaturated fatty acids (PUFA) of the $n-6$ and $n-9$ series are involved in the genesis of hyper adiposity, dyslipidemia, and insulin resistance ${ }^{11}$.

Hyperlipidic ( $\mathrm{HL}$ ) diets enriched with either soy or fish oil, which are rich in n-6 and n-3 PUFAs, respectively, have been used. The HL diets were given to the animals for 8 weeks, starting at weaning, and were prepared by adding, to the control diet (rat balanced chow, 5\% fat, 20\% protein, w/w, $2.8 \mathrm{Kcal} / \mathrm{g}$ ), the necessary amount of oil and also of casein to match the protein content of the control chow ${ }^{13,14}$.

When the caloric density of the $\mathrm{HL}$ diet was $4.9 \mathrm{Kcal} / \mathrm{g}$ (30\% from fat), only the fish diet induced excess weight gain ${ }^{13}$. On the other hand, neither the soy nor the fish diet induced obesity when yielding only $3.6 \mathrm{kcal} / \mathrm{g}(40 \% \text { from fat })^{14}$. An important observation was that the plasma lipid profile was not altered in the animals made obese by the fish $\operatorname{diet}^{13}$. Also, in neither case was hyperphagia observed. The daily intake of the $\mathrm{HL}$ diets was actually decreased in a way that energy intake was normal. This indicates that hypometabolism rather than hyperphagia contributed to the increased adiposity induced by the fish diet ${ }^{13,14}$.
The development of a non-hyperphagic obesity has also been observed using a palatable $\mathrm{HL}$ diet $(5.0 \mathrm{kcal} / \mathrm{g}, 35 \%$ from fat) prepared by adding chocolate, peanuts, and biscuits to the control chow. However, unlike the fish diet, this cafeteria diet induced dyslipidemia ${ }^{15}$.

\section{Intrauterine undernutrition and obesity}

It is accepted that the survival to malnutrition during foetal and/or neonatal life depends on growth and metabolic adaptations, with the establishment of a "thrifty phenotype". Once developed, this economic metabolism may become programmed and predispose to body energy deposition in later life, especially if combined with a good postnatal nutrition. In humans, several adulthood pathologies have been associated to poor early life nutrition, such as cardiovascular diseases, insulin resistance with type Il diabetes, and obesity. Numerous undernutrition protocols have been described to study the consequences of intrauterine/perinatal undernutrition in rats. They differ in terms of timing, severity, and type of malnutrition, i.e., whether a protein or a protein/energy restriction is applied. Importantly, these differences do have impacts on the final phenotype ${ }^{16}$.

The hypothalamic actions of insulin and serotonin have been evaluated in adult rats food restricted intrauterus. During the first 2 weeks of pregnancy, the dams received only $50 \%$ of the food amount consumed by the control dams. During the last week of pregnancy and lactation, they were pair-fed to the control dams, to avoid compensatory hyperphagia. Their four-month-old male and female progeny was studied. Gender differences were detected, as only the restricted females developed increased body fatness and leptinemia. Although both genders had impairment of insulin- and serotonin-induced hypophagia, the females were more affected ${ }^{17,18}$.

Interestingly, impairment of the hypophagia induced by insulin or serotonin, in the absence of 
obesity, has also been seen in adult male rats whose mothers ate a normocaloric diet rich in trans fatty acids ${ }^{19}$.

\section{Estimating neurotransmitter release: brain microdialysis}

The understanding of diet interactions with the brain systems involved in the regulation of energy balance is of great interest. In our hands, the combination of in vivo microdialysis, to sample brain intracellular fluid, and HPLC with electrochemical detection (EC), to measure serotonin levels in the microdialysate samples, has yielded numerous data on the participation of the serotonergic system in the physiology and pathophysiology of feeding control15,5, 10,18,20-22.

The microdialysis technique (MD) is based on the principle of dialysis, in which a semi permeable membrane separates two compartments while allowing a bidirectional flow of solutes between them. The membrane is placed in the brain tissue and perfused internally with an isotonic physiological solution (called artificial cerebrospinal fluid, (SF). After equilibration between the two compartments, the composition of the collected microdialysate reflects that of the brain extracellular fluid. The microdialysis perfusion thus provides a way to monitor in vivo neurochemistry of specific brain regions and it has been widely used to estimate neurotransmitter release $\mathrm{e}^{23-27}$.

A less explored but also useful feature of the technique is that it allows the supplying of a substance or drug to the tissue, by adding it to the perfusing solution, a feature known as reverse dialysis or retrodialysis. Brain MD is also applicable to humans. Monitoring of brain metabolism, through determination of glucose, lactate, and pyruvate levels during brain surgeries, has been one of its applications ${ }^{23-27}$. These latter aspects will not be considered in the following text.

The fact that brain MD is suitable for continuous perfusion of a brain site in the awake, freely-moving animal, has made the technique very appropriate for behavioral studies. The MD set up for an experiment in rats or mice must include a perfusion pump, an MD probe, and an analytical device to determine dialysate levels of the substance of interest (Figure 1). Additionally, although not mandatory, it is advisable that the animal is connected to a counterbalanced arm and swivel system, allowing probe perfusion without any disturbances to movements and normal behavior.

In the microdialysis probe, the membrane is mounted in a way to allow its implantation in the brain, its perfusion with isotonic CSF via the inlet tube, and the collection of the dialysate via the outlet tube. There are commercially available MD probes but many laboratories custom made their own devices, what can greatly lower the costs of an MD experiment, even considering that some probe parts are only available from foreign suppliers. Unfortunately, the recovery capacity of these home made probes is usually lower than that of the industrialized ones. Figure 1 shows a schematic drawing of the MD probe as manufactured at Unifesp.

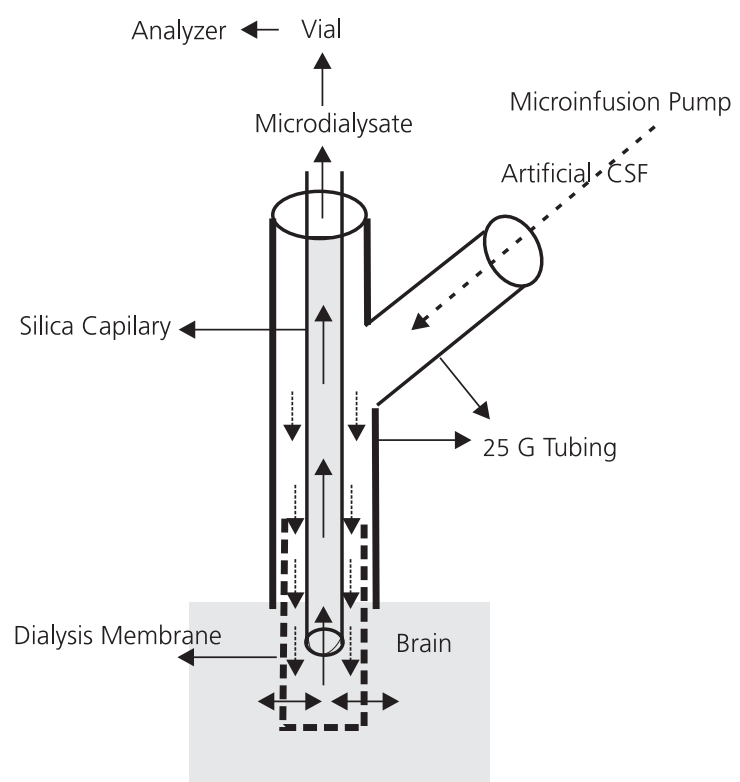

Figure 1. Schematic representation of the concentric microdialysis probe (not drawn to scale). Probe assembly was detailed elsewhere ${ }^{5,20}$ 
Probe recovery, i.e., the amount of the substance of interest that actually enters the microdialysate and becomes available for detection, is a key characteristic of the MD experiment. Absolute probe recovery is directly proportional to perfusion rate and to membrane length. However, because molecules in ECF must equilibrate across the MD membrane, the relative recovery decreases with increasing flow rates. It is thus important that these aspects are examined, as they can be modified to meet the needs of a particular experiment. In general, rat brain MD experiments apply flow rates in the range of 1.0 to $3.0 \mu \mathrm{l} / \mathrm{min}$. and membrane lengths between of 1.0 to $4.0 \mathrm{~mm}$, depending on the brain area. Typically, each dialysate sample is collected for 10 to $20 \mathrm{~min}^{23-27}$.

Potentially, every substance recovered to the microdialysate sample can be quantitated, provided that a sufficiently sensitive analytical method is used. This is usually an important issue, due to the small volumes of dialysate obtained and the low amount of analytes in the sample. However, as the passage through the MD membrane excludes large molecules, such as large proteins, MD samples have the advantage of being highly purified, making it unnecessary to prepare the sample before analysis.

Numerous brain MD studies have focused on monoaminergic and cholinergic transmission, and HPLC coupled with electrochemical detection (EC) has been the method of choice to determine neurotransmitter levels in MD samples. This method has been used to determine the levels of serotonin and its main metabolite ( 5 -HIAA) in MD samples collected from the hypothalamus. Because it is present in very low amounts in the hypothalamic microdialysates (in the order of fentomols), serotonin requires a high sensitivity method to be detected and HPLC-EC conditions able to maximize the capacity to measure this amine have been adopted $5,6,10,18,20-22$.

Using this approach, it has been shown that serotonin release in the lateral hypothalamus was stimulated by the ingestion of food, suggesting a physiological mechanism elicited to achieve satiety. This modulatory response was preserved in MSG-obese rats. On the other hand, obese Zucker rats had an exacerbated serotonergic response to food, probably due to resistance to the released neurotransmitter. A similar profile was found in female adult rats undernourished in utero, which were obese, had impairment of serotonin hypophagia and enhanced release of serotonin in response to a meal $15,5,6,18$.

The putative interactions of serotonin with leptin, NPY, and interleukin-1b have also been evaluated. A single intracerebroventricular leptin injection failed to affect serotonin release but potentiated the food-induced serotonin release while inhibiting food ingestion. NPY, a potent orexigenic factor, had a dual effect on LH serotonin. When a low dose was given i.c.v., serotonin release was stimulated as the animal ingested food. However, higher NPY doses induced higher intakes but blocked serotonin release. These findings indicated that the serotonergic system is involved in the effects elicited by leptin and NPY in normal rats. Additionally, in obese Zucker rats it has been found that the hypophagia induced by interleukin- $1 \mathrm{~b}$ depends on the serotonin released in the medial hypothalamus and that the nitric oxide system counteracts this effect $t^{1,10,21,22}$.

As already pointed out, the brain MD sample is a rich source of information, since it contains a multitude of substances recovered from the tissue. Our studies are currently being expanded by the implementation of the methodologies for detection of glucose (by the glucose oxidase method) and nitric oxide (by chemiluminescense) in the microdialysates.

\section{Detecting brain proteins: immunoblot and proteomics}

Analytical methods based on protein detection are broadly used. Immunoblot (also called Western blot) is a semi-quantitative method based on the binding of the protein of interest to a specific antibody. The first step is to prepare a 
tissue extract by homogenizing a fragment in the appropriate buffer containing protease inhibitors. After centrifugation, the supernatant is loaded on a polyacrylamide gel to which an electrical potential is applied, leading to the separation of the proteins in individual bands, as they migrate on the gel on the basis of their size (molecular weight). This procedure is known as SDS-PAGE (sodium dodecyl sulfate polyacrylamide gel electrophoresis).

The so resolved proteins are transferred from the gel medium to a nitrocellulose membrane and this sheet is incubated with the specific antibody, directed against the protein of interest. This primary antibody binds to the protein (band) and the reaction can be detected by various ways. One sensitive detection method is the application of a secondary antibody conjugated with the enzyme horseradish peroxidase (HRP). The secondary antibody is an $\lg \mathrm{G}$ directed against the animal species in which the primary antibody was raised. It binds to the primary antibody and is developed by chemiluminescence, after the addition of a substrate for the HRP, usually luminol, in the presence of hydrogen peroxide. By exposing the blot to an X-ray film, the bands are visualized and further quantitated by densitometry, the results being usually expressed as arbitrary densitometric units. As the method is semi quantitative, it is important that each gel includes samples from all the groups being compared in an experimental design ${ }^{28,29}$.

Immunoblot applications in the field of brain control of food intake are wide. This method has been used to determine hypothalamic levels of the serotonin receptor proteins, of the $5-\mathrm{HT} 1 \mathrm{~B}$ and $5-\mathrm{HT} 2 \mathrm{C}$ subtypes, and also of the serotonin transporter protein. It was possible to demonstrate that these protein levels were affected in the hypothalamus of rats fed hyperlipidic diets and also in adult rats undernourished in uterus ${ }^{14,18}$.

Proteins involved in the transmission of the insulin signal in the hypothalamus may also be quantitated by immunoblot. Additionally, it is possible to evaluate the ability of insulin to stimulate its signaling pathway by determining the level of phosphorylation of these signaling proteins. The hypothalamic, anorexigenic action of insulin, has been shown to depend on the activation of the phosphatidylinositol 3-kinase (PI3-K) pathway. Insulin binding to its receptor (IR) induces its autophosphorylation and activates its tyrosine kinase activity towards receptor substrates, such as IR substrate-1 (IRS-1) and IR substrate-2 (IRS-2). Phosphorylated IRSs activate PI3-K, leading to the phosphorylation of protein kinase B (or Akt, a serine/threonine kinase) ${ }^{2}$. By using antiphosphotyrosine as the primary antibody, it is possible to estimate the activation of the initial steps of insulin signaling, i.e., IR and IRSs tyrosine phosphorylation. With this approach, impairment of insulin signaling has been demonstrated in the hypothalamus of obese Zucker rats and of rats undernourished or fed with trans fatty acids intra uterus $5^{9,17,19}$

Finally, the perspectives of a novel and promising method in nutrition research, namely the proteomic analysis, will be commented. The term proteomics designates the analysis of the complement of proteins (or the proteome) of a tissue, organ or organism. It has advantages over the analysis of gene expression, as it allows the evaluation of the proteins actually produced, with their post transcriptional and post translational modifications. There are various described proteomics methods. In the 2D-PAGE MALDI-TOF MS, the analysis starts with a two-dimensional separation of the proteins. In the first dimension (isoelectric focusing), proteins are separated according to their net charge (isoelectric point). The second dimension is a SDS-PAGE, with separation by size.

The proteins appear as spots after the staining of the gel. An image analysis software allows the identification of the spots with different densities between treatment groups, indicating the proteins whose expression was modified by the treatments applied. As the analysis is comparative, every set of gels must contain one sample from each treatment group included in the experimental 
design. The spots of interest are selected and enzymatically digested, the peptide fragments extracted and analyzed by mass spectrometry (MS). The preparation of the peptides for MS involves their evaporation and ionization, by the method of matrix-assisted laser desorption ionization (MALDI). The separation of the ionized peptides occurs in high vacuum, according to their mass-to-charge ratios, which determines their time-of-flight (TOF) to reach the detector. The fragments are compared to a protein bank and the results expressed as a probability score of identity of the protein ${ }^{30,31}$.

At Unifesp, with the supervision of the group of Dr. Dulce Elena Casarini, the methodology for proteomic analysis of hypothalamic extracts, from rats fed chronically with modified diets, has just been established. It is anticipated that the results will lead to important insights into the complex interactions of diet components and hypothalamic proteins and help the understanding of the complex pathophysiology of obesity.

\section{A C KNOWLEDGEMENTS}

The work described herein was supported by grants from the Brazilian agencies: Fundação de Amparo à Pesquisa do Estado de São Paulo (FAPESP), Conselho Nacional de Desenvolvimento Científico e Tecnológico (CNPq), and Coordenação de Pesquisa de Pessoal de Nível Superior (CAPES).

In references 7, 13, and 15, E. B. Ribeiro was a colaborator in the group of Dr. Claudia MO Nascimento and Dr. Lila M Oyama, Universidade Federal de São Paulo.

In reference 9, E.B. Ribeiro was a colaborator in the group of Dr. José BC Carvalheira, Dr. Lício A Velloso and Dr. Mário JA Saad, Universidade Estadual de Campinas.

\section{RE FER E N C E S}

1. Ribeiro EB, Telles MM, Oyama LM, Silveira VLF, Nascimento CMO. Hypothalamic serotonin in the control of food intake: physiological interactions and effect of obesity. In: Starks TP, editor. Focus on nutrition research. New York: New Science Publishers; 2005.

2. Velloso LA. The hypothalamic control of feeding and thermogenesis: implications on the development of obesity. Arq Bras Endocrinol Metab. 2006; 50(2):165-76.

3. Ribeiro EB, Marmo MR, Andrade IS, Dolnikoff MS. Effect of fasting on monosodium glutamate-obese rats. Braz J Med Biol Res. 1989; 22(7):917-21.

4. Ribeiro EB, Nascimento CMO, Andrade IS, Hirata $A E$, Dolnikoff MS. Hormonal and metabolic adaptations to fasting in monosodium glutamate obese rats. J Comp Physiol B. 1997; 167(6):430-7.

5. Mori RCT, Guimarães RB, Nascimento CMO, Ribeiro EB. Lateral hypothalamic serotonergic responsiveness to food intake in rat obesity as measured by microdialysis. Can J Physiol Pharmacol. 1999; 77(4):286-92.

6. Guimarães RB, Telles MM, Coelho VBO, Mori RCT, Nascimento CMO, Ribeiro EB. Adrenalectomy abolishes the food-induced hypothalamic serotonin release in both normal and monosodium glutamate-obese rats. Brain Res Bull. 2002; 58(4):363-9.

7. Bueno AA, Oyama LM, Estadella D, Habitante CA, Bernardes BS, Ribeiro EB, et al. Lipid metabolism of monosodium glutamate obese rats after partial removal of adipose tissue. Physiol Res. 2005; 54(1): 57-65.

8. Phillips MS, Liu Q, Hammond HA, Gugan V, Hey PJ, Caskey $C T$, et al. Leptin receptor missense mutation in the fatty Zucker rat. Nature Gen. 2006; 13(1): 18-19.

9. Carvalheira JBC, Ribeiro EB, Telles MM, Gontijo JAR, Velloso LA, Saad MJA. Selective impairment of insulin signaling in the hypothalamus of obese Zucker rats. Diabetologia. 2003; 46(12):1629-40.

10. Iuras A, Telles MM, Bertoncini CRA, Ko GM, Andrade IS, Silveira VLF, et al. Central administration of a nitric oxide precursor abolishes both the hypothalamic serotonin release and the hypophagia induced by interleukin $1 B$ in obese Zucker rats. Regul Pept. 2005; 124(1-3):145-50.

11. Buettner R, Scholmerich J, Bollheimer LC. High-fat diets: modeling the metabolic disorders of human obesity in rodents. Obesity. 2007; 15(4):798-808.

12. Berthoud HR. Neural control of appetite: cross-talk between homeostatic and non-homeostatic systems. Appetite . 2004; 43(3):315-17.

13. Gaiva MHG, Couto RC, Oyama LM, Couto GEC, Silveira VLF, Ribeiro EB, et al. Polyunsaturated fatty acids rich diets: I -effect on body weight gain and adipose tissue metabolism in rats. Br J Nutr. 2001; 86(3):371-7 
14 Watanabe RLH, Telles MM, Ribeiro EB. Chronic consumption of hyperlipidic diet rich in omega 3 fatty acids: effect on hypothalamic serotonininduced hypophagia [abstract]. Obes Rev. 2005; 6 (Suppl 1):56.

15. Estadella D, Oyama LM, Damaso AR, Ribeiro EB, Nascimento CMO. Effect of palatable hyperlipidic diet on lipid metabolism of sedentary and exercised rats. Nutrition. 2004; 20(2):218-24.

16. Cripps RL, Martin-Gronert MS, Ozanne SE. Fetal and perinatal programming of appetite. Clin Sci. 2005; 109(1): 1-11.

17. Sardinha FLC, Telles MM, Albuquerque KT, Oyama LM, Guimarães PAMP, Santos OFP, et al. Gender difference in the effect of intrauterine malnutrition on the central anorexigenic action of insulin in adult rats. Nutrition. 2006; 22(11-12):1152-61.

18. Pôrto LCJ, Sardinha FLC, Telles MM, Guimarães $\mathrm{RB}$, Albuquerque KT, Andrade IS, et al. Impairment of the serotonergic control of feeding in adult female rats exposed to intra-uterine malnutrition. Br J Nutr. 2008; 12:1-7. doi:10.1017/S000711450 8061503.

19. Albuquerque KT, Sardinha FLC, Telles MM, Watanabe RLH, Nascimento CMO, Carmo MGT, et al. Intake of trans fatty acid-rich hydrogenated fat during pregnancy and lactation inhibits the hypophagic effect of central insulin in the adult offspring. Nutrition. 2006; 22(7-8):820-9.

20. Ribeiro EB, Betttiker RL, Bogdanov M, Wurtman RJ. Effect of nicotine on serotonin release in rat brain. Brain Res. 1993; 621(2):311-8.

21. Telles MM, Guimarães RB, Ribeiro EB. Effect of leptin on the acute feeding-induced hypothalamic serotonergic stimulation in normal rats. Regul Pept. 2003; 115(1):11-18.

22. Mori RCT, Telles MM, Guimarães RB, Novo NF, Juliano $Y$, Nascimento $C M O$, et al. Feeding induced by increasing doses of neuropeptide $Y$ : dual effect on hypothalamic serotonin release in normal rats. Nutr Neurosci. 2004; 7(4):235-9.

23. Ungersted $U$. Microdialysis: principles and applications for studies in animals and man. J Int Med. 1991; 230(4):365-73.

24. Khan S-N, Shuaib A. The technique of intracerebral microdialysis. Methods. 2001; 23(1):3-9.

25. Horn TFW, Engelman M. In vivo microdialysis for nonapeptides in rat brain: a practial guide. Methods. 2001; 23(1):41-53.

26. Tisdall MM, Smith M. Cerebral microdialysis: research technique or clinical tool. $\mathrm{Br} J$ Anaesth. 2006; 97(1):18-25.

27 Westerink B, Cremers T, editors. Handbook of microdialysis. methods, applications and perspectives. Amsterdam: Elsevier; 2007.

28. Kurien BT, Scofield RH. Protein blotting: a review. J Immunol Methods. 2003; 274(1-2):1-15.

29 Kurien BT, Scofield RH. Western blotting. Methods. 2006; 38(4):283-93.

30. Wang J, Li D, Lawrence JD, Wu G. Proteomics and its role in nutrition research. J Nutr. 2006; 136(7) 1759-62.

31. Schweigert FJ. Nutritional proteomics: methods and concepts in nutritional science. Ann Nutr Metab. 2007; 51(2):99-107. 
